\title{
Lipid-soluble polyphenols from sweet potato exert antitumor activity and enhance chemosensitivity in breast cancer
}

\author{
Kazuhiro Kato, ${ }^{1, *}$ Masaki Nagane, ${ }^{1, \#}$ Naoyuki Aihara, ${ }^{2}$ Junichi Kamiie, ${ }^{2}$ Masakatsu Miyanabe, ${ }^{3}$ Shinobu Hiraki, ${ }^{3}$ \\ Xiaolin Luo, ${ }^{3}$ Ikuo Nakanishi, ${ }^{4}$ Yoshimi Shoji, ${ }^{4}$ Ken-ichiro Matsumoto, ${ }^{4}$ and Tadashi Yamashita ${ }^{1, *}$ \\ ${ }^{1}$ Laboratory of Biochemistry and ${ }^{2}$ Laboratory of Veterinary Pathology, School of Veterinary Medicine, Azabu University \\ 1-17-71, Fuchinobe, Sagamihara, Kanagawa 252-5201, Japan \\ ${ }^{3}$ Genuine R\&D Co., Ltd., 2-36-12, Takamidai, Higashi-ku, Fukuoka 811-0215, Japan \\ ${ }^{4}$ Quantitative RedOx Sensing Group, Department of Basic Medical Sciences for Radiation Damages, National Institute of Radiological Sciences (NIRS), \\ Quantum Medical Science Directorate, National Institutes for Quantum and Radiological Science and Technology (QST), \\ 4-9-1 Anagawa, Inage-ku, Chiba 263-8555, Japan
}

(Received 30 April, 2020; Accepted 7 August, 2020; Published online 16 January, 2021)

Polyphenols are abundant in vegetables and fruit. They have been shown to have various antitumor, antioxidant, and antiinflammatory effects. Here, we extracted the lipid-soluble fraction of polyphenols from fermented sweet potato (Ipomoea batatas). These lipid-soluble polyphenols mainly contained caffeic acid derivatives with strong antioxidant ability, which we hypothesized to affect diseases for which oxidative stress is a factor, such as cancer. We therefore investigated the antitumor and chemosensitizing effects of lipid-soluble polyphenols on E0771 murine breast cancer cells. The lipid-soluble polyphenols accumulated in the cells' cytoplasm due to its high lipophilicity, and reduced reactive oxygen species through its strong antioxidant activity. The lipid-soluble polyphenols also arrested the cell cycle at $\mathbf{G}_{0} / \mathbf{G}_{1}$ by suppressing Akt activity, and enhanced the cytotoxicity of anticancer agents. In this model, lipid-soluble polyphenols inhibited tumor growth and enhanced the efficacy of chemotherapy drugs. These results suggest the potential of lipid-soluble polyphenols as a functional food to support cancer therapy.

Key Words: polyphenol, breast cancer, functional food, chemotherapy, antioxidant

$\mathrm{P}$ olyphenols reportedly have antitumor, antioxidant, antiinflammatory, and cardiovascular-protective effects, ${ }^{(1-4)}$ which are thought to result from modulation of molecular targets and signaling related to cell survival, proliferation, differentiation, migration, and angiogenesis. ${ }^{(5)}$ Therefore, polyphenols have the potential to become natural anticancer agents.

Various polyphenols with antioxidant activity are present in tubers of Ipomoea batatas, known as the sweet potato. ${ }^{(6,7)}$ Fermented potato pulp also contains alkyl ferulates, a kind of polyphenol that is lipid-soluble and has antioxidant activity. ${ }^{(8)}$ Therefore, we fermented sweet potatoes and extracted the lipidsoluble polyphenol fraction. Lipid-soluble polyphenols (PPL) mainly contains caffeic acid derivatives such as caffeic acid ethylester and caffeic acid cetyl-ester, as strong antioxidant components, which are reported to inhibit growth of some cancer cells, and to inhibit lipid oxidation. ${ }^{(9)}$ PPL is a novel polyphenol that is expected to have high cellular affinity and absorbability.

Among woman around the world, breast cancer (BC) is the most commonly diagnosed cancer the leading cause of cancer death. ${ }^{(10)}$ Surgical resection is the first treatment choice for BC, with chemotherapy and radiotherapy typically used to eliminate residual tumor cells, suppress tumor growth, and prevent recurrence. Although these adjuvant therapies improve overall survival and quality of life for patients with $\mathrm{BC},{ }^{(11)}$ they often have adverse effects, such as myelosuppression from carboplatin, ${ }^{(12)}$ neuropathy from vincristine, ${ }^{(13)}$ and dermatitis from radiotherapy. ${ }^{(14)}$ To reduce these side effects, chemosensitizers and radiosensitizers have been studied. ${ }^{(15,16)}$ The discovery of bioactive natural products with antitumor and chemo-sensitizing effects might therefore provide complementary strategies for treating BC.

In this study we evaluated the antitumor effects of PPL on BC and the effects of combining PPL with chemotherapy drugs. We found PPL to function as an antioxidant with antitumor effects despite its low toxicity, both in vitro and in vivo, and to enhance the efficacy of chemotherapy agents.

\section{Materials and Methods}

Reagents. The PPL was manufactured by Genuine R\&D Co., Ltd. (Tokyo, Japan). The amount of caffeic acid derivatives in PPL was analyzed by TLC densitometry method as described previously (Table 1). ${ }^{(8)}$ We purchased carboplatin (CBDCA; Cat. No. C2538) from Sigma-Aldrich, (St. Louis, MO); vincristine sulfate (VCR; Cat. No. V5254) from LKT Laboratories, Inc. (St. Paul, MN); N-Acetyl-L-cysteine (NAC; Cat. No. 015-05132) and 2,2-diphenyl-1-picrylhydrazyl radical (DPPH; Cat. No. 044150) from Wako Pure Chemical Industries (Osaka, Japan); and acetonitrile [MeCN; Cat. No. 00433-95; spectral grade; used (as received) as a solvent for DPPH] from Nacalai Tesque, Inc. (Kyoto, Japan).

Cell culture. We maintained mouse BC E0771 cells (Cat. \#94A001, CH3 BioSystems, NY) in RPMI-1640 medium (Cat. No. 189-02025, Wako Pure Chemical Industries) supplemented with $10 \%$ fetal bovine serum (FBS) and $10 \mathrm{mM}$ HEPES buffer solution (Cat. No. 345-06681, Wako Pure Chemical Industries) at $37^{\circ} \mathrm{C}, 5 \% \mathrm{CO}_{2}$.

We maintained human BC MDA-MB-231 cells (Cat. No. ATCC $^{\circledR}$ HTB-26 ${ }^{\mathrm{TM}}$, ATCC, Manassas, VA) in DMEM (Cat. No.

Table 1. The amount of caffeic acid derivatives in PPL

\begin{tabular}{lc}
\hline \multicolumn{2}{c}{ Caffeic acid derivatives (\%) } \\
\hline Caffeic acid ethyl ester & 2.51 \\
Caffeic acid cetyl ester & 0.8 \\
\hline
\end{tabular}

\#These authors contributed equally to this work

*To whom correspondence should be addressed.

E-mail: yamashita@azabu-u.ac.jp 
043-30085, Wako Pure Chemical Industries) supplemented with $10 \% \mathrm{FBS}$ at $37^{\circ} \mathrm{C}, 5 \% \mathrm{CO}_{2}$.

Confocal laser microscope. E0771 cells were seeded in 35$\mathrm{mm}$, poly-L-lysine-coated, glass-bottomed dishes (Cat. D111310, Matsunami Glass Ind., Ltd., Osaka, Japan) and cultured overnight. After treatment with $50 \mu \mathrm{M}$ PPL for $48 \mathrm{~h}$, fluorescence images of live cells were taken with a Leica TCS SP5 confocal laser microscope (Leica, Heidelberg, Germany). PPL was visualized at Excitation/Emission $=331 \mathrm{~nm} / 427 \mathrm{~nm}$.

Intracellular reactive oxygen species (ROS) detection.

Intracellular oxidative stress was evaluated by staining with $2^{\prime}, 7^{\prime}-$ dichlorofluorescin diacetate (DCFDA; Cat. No. D6883, SigmaAldrich), as previously reported. ${ }^{(17)}$ Cells were treated with PPL or NAC for $24 \mathrm{~h}$. After treatment, cells were stained with $20 \mu \mathrm{M}$ DCFDA for $30 \mathrm{~min}$ at $37^{\circ} \mathrm{C}$. Cells were analyzed for fluorescence intensity using an EC800 Analyzer (Sony Biotechnology, Tokyo, Japan).

DPPH assay. Rates of DPPH-scavenging reactions by PPL or NAC were determined by monitoring absorbance changes at $519 \mathrm{~nm}$ from DPPH, using a stopped-flow technique on a Unisoku RSP-1000-02NM spectrophotometer at $25^{\circ} \mathrm{C} .^{(18)}$ The pseudo-firstorder rate constants $\left(k_{\text {obs }}\right)$ were determined by a least-squares curve fit. The first-order plots of $\ln \left(A-A_{\infty}\right)$ vs time $\left(A+A_{\infty}\right)$ were denoted as the absorbance at the reaction time and the final absorbance, respectively, and were linear until three or more half-lives were seen with correlation coefficients $\rho>0.999$. In each case, rate constants derived from at least three independent measurements agreed within an experimental error of $\pm 5 \%$.

Clonogenic survival assay. A clonogenic survival assay to determine the cytotoxicity of PPL was performed as previously described. ${ }^{(19)}$ Cells were trypsinized, diluted, counted, and seeded into $60-\mathrm{mm}$ dishes at densities of 200-5,000 cells/dish before being allowed to adhere in a $37^{\circ} \mathrm{C}$ incubator. After $16 \mathrm{~h}$, cells were incubated with PPL, anticancer agents, or anticancer agents + PPL or NAC for $48 \mathrm{~h}$. Cells were then allowed to grow in a humidified $5 \% \mathrm{CO}_{2}$ atmosphere at $37^{\circ} \mathrm{C}$ for 5 days before being fixed with methanol and stained with $0.03 \%$ crystal violet solution (Wako Pure Chemical Industries). Colonies that containing more than 50 cells were scored as surviving cells. The survival curves and $\mathrm{IC}_{50}$ were calculated using Prism8 Software (GraphPad Software Inc., La Jolla, CA).

Cell-cycle analysis. To analyze cell-cycle perturbation, DNA was stained with propidium iodide and the cells were analyzed by flow cytometry. ${ }^{(20)}$ Cells were incubated with PPL for $48 \mathrm{~h}$. We resuspended $0.5 \times 10^{6}$ cells in PBS and fixed them in ice-cold $70 \%$ ethanol for at least $6 \mathrm{~h}$. Fixed cells were washed in PBS twice, and incubated with propidium iodide staining solution $(50 \mu \mathrm{g} / \mathrm{ml}$ propidium iodide, $5 \mu \mathrm{g} / \mathrm{ml}$ RNase I, $137 \mathrm{mM} \mathrm{NaCl}$, $2.7 \mathrm{mM} \mathrm{KCl}, 8.1 \mathrm{mM} \mathrm{Na}_{2} \mathrm{HPO}_{4}$, and $1.47 \mathrm{mM} \mathrm{KH}_{2} \mathrm{PO}_{4}$ ) at $37^{\circ} \mathrm{C}$ for $30 \mathrm{~min}$. The DNA content of at least 10,000 cells/sample was analyzed using an EC800 Analyzer (Sony Biotechnology) and FlowJo software (BD Biosciences, CA).

Sodium dodecyl sulfate-polyacrylamide gel electrophoresis (SDS-PAGE) and Western blotting. We performed SDS-PAGE and Western blotting as previously described. ${ }^{(21)}$ Briefly, cells were collected and lysed in modified RIPA buffer following sonication using a Bioruptor 2 (Sonic Bio Inc., Kanagawa, Japan). Proteins were separated by SDS-PAGE and transferred onto a PVDF membrane (Immobilon-P, Millipore Corp., Bedford, MA). Transfer conditions were $100 \mathrm{~V}$ in Towbin buffer $(25 \mathrm{mM}$ Tris, $192 \mathrm{mM}$ glycine, $1 \% \mathrm{SDS}$, and $20 \%$ methanol) for $60 \mathrm{~min}$ at $4{ }^{\circ} \mathrm{C}$. The membrane was probed with specific antibodies diluted with TBST $[10 \mathrm{mM}$ Tris- $\mathrm{HCl}(\mathrm{pH} 7.4), 0.1 \mathrm{M} \mathrm{NaCl}$ and $0.1 \%$ Tween-20] containing 5\% BSA or skim milk, overnight at $4{ }^{\circ} \mathrm{C}$. After probing with horseradish peroxidase (HRP)-conjugated secondary antibodies, bound antibodies were detected with Immobilon Western HRP substrate. Densitometry was performed using ImageJ software (NIH, Bethesda, MD). For Western blotting, we used anti-Akt (Cat. No. \#4691S, Cell Signaling Technology, Beverly, MA), anti-Akt-pSer473 (Cat. No. \#4060S), anti- $\beta$-Actin-Peroxidase (Cat. No. A3854, Sigma-Aldrich), and goat anti-rabbit $\operatorname{IgG}(\mathrm{H}+\mathrm{L})$ (Cat. No. \#A16110, Thermo Fisher Scientific, Tokyo, Japan) as HRP-conjugated secondary antibodies. Immobilon Western HRP substrate was purchased from Merck Millipore (Billerica, MA).

General animal methods. All animal experiments were performed according to the established guidelines of the "Law for the Care and Welfare of Animals in Japan," and approved by the Animal Experiment Committee of Azabu University (No. 190507 $3)$. Mice were housed in plastic cages in an air-conditioned room at $24^{\circ} \mathrm{C}$ in a $12 \mathrm{~h}$ light-dark cycle (light on at 7:00 am) with food and water available ad libitum in SPF conditions. Tumorbearing mice were ethically sacrificed when tumor volume reached $1,500 \mathrm{~mm}^{3}$ (or $\sim 1.5 \mathrm{~cm}$ in any dimension); tumor burden became $>10 \%$ of the body weight; tumors ulcerated, became necrotic or infected; a tumor impeded the animal's ability to move its limbs and assume normal body postures; or an animal became moribund, cachectic, or unable to obtain food or water. At the end of experiments, animals were anesthetized with $2 \%$ isoflurane and sacrificed by cervical dislocation. Death was determined by confirming that dislocation took place if the animal's head hung loosely from its body.

Tumor transplantation and experimental therapy.

Female C57BL/6N mice, aged 6-8 weeks, were maintained and bred in the animal facility of Azabu University. For allograft transplantation, two million E0771 cells were inoculated subcutaneously into the mammary gland of each mouse. Tumor volume was calculated as $\mathrm{V}\left(\mathrm{mm}^{3}\right)=\pi / 6 \times$ length $\times$ width $^{2}$ (length: largest tumor diameter; width: perpendicular tumor diameter). When tumor volume reached $100-200 \mathrm{~mm}^{3}$ (8 days after transplantation), PPL suspended in methyl cellulose (Cat. No. 131-17811, Wako Pure Chemical Industries) was orally administered to the mice $(6 \mathrm{mg} / \mathrm{kg} /$ day $)$ for 7 consecutive days; and CBDCA was intraperitoneally administered at a single dose $(120 \mathrm{mg} / \mathrm{kg} / \mathrm{day})$ on Day 8 after transplantation.

Immunohistochemistry. Histological analysis was performed as previously described. ${ }^{(22)}$ Tumor tissues were excised and fixed with $4 \%$ buffered formaldehyde, embedded in paraffin, and sliced into $5-\mu \mathrm{m}$ sections. After being deparaffinized, slides were immersed in citrate buffer and continued to antigen activation at $120^{\circ} \mathrm{C}$ for $2.5 \mathrm{~min}$ using a pressure cooker. Next, slides were immersed in $3 \%$ hydrogen peroxide solution for $20 \mathrm{~min}$ to remove endogenous peroxidase. After blocking non-specific binding sites, slides were probed with anti-cleaved caspase-3 (Cat. No. \#9664, Cell Signaling Technology) overnight. Slides were then incubated with HRP-conjugated secondary antibody (Cat. No. 414321, Nichirei Bioscience, Tokyo, Japan). After coloring with a DAB substrate kit with hydrogen peroxide (Cat. No. SK-4100, Vector, Burlingame, CA), slides were stained with hematoxylin and sealed after dehydration. Images were taken with a BZ-X700 microscope (Keyence, Osaka, Japan).

Statistical analysis. All values are expressed as means \pm SD of 3-5 independent experiments. Differences between groups were evaluated by Student's $t$ tests (two-sided) or Tukey-Kramer tests. $P<0.05$ was considered significant.

\section{Results}

PPL reduces intracellular oxidative stress and has strong antioxidant activity. To evaluate PPL cytotoxicity, we used clonogenic survival assays. E0771 cells were treated with PPL for $48 \mathrm{~h}$. The $\mathrm{IC}_{50}$ of PPL against E0771 cells was approximately $116 \mu \mathrm{M}$ (Fig. 1A). As PPL can emit $427 \mathrm{~nm}$ fluorescence from $331 \mathrm{~nm}$ excitation light, we visualized intracellular PPL uptake by a confocal laser microscope. As shown in Fig. 1B, PPL was localized in the cytoplasm of E0771 cells. Cellular ROS levels 


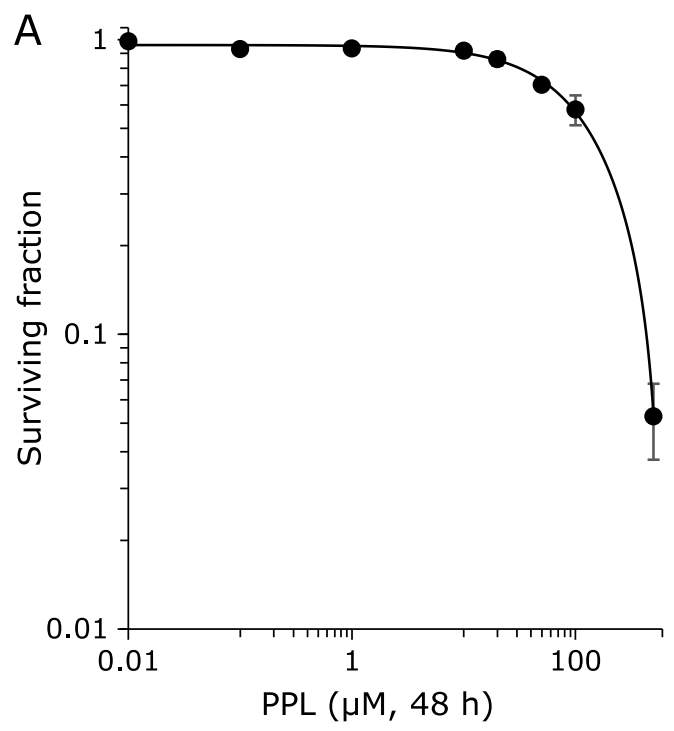

B
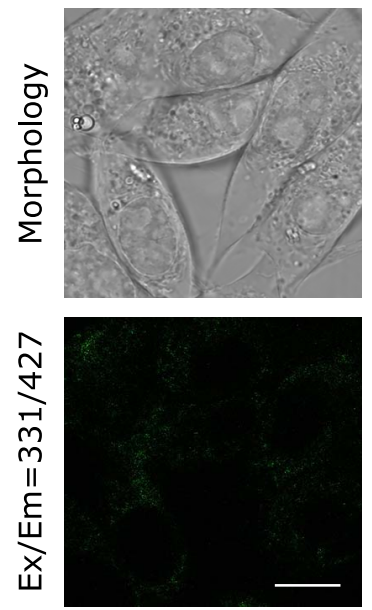

PPL $50 \mu \mathrm{M} 48 \mathrm{~h}$
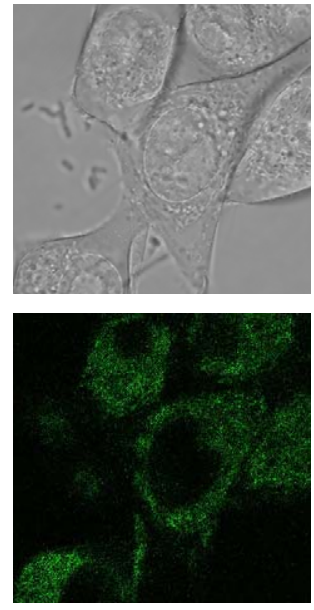

C
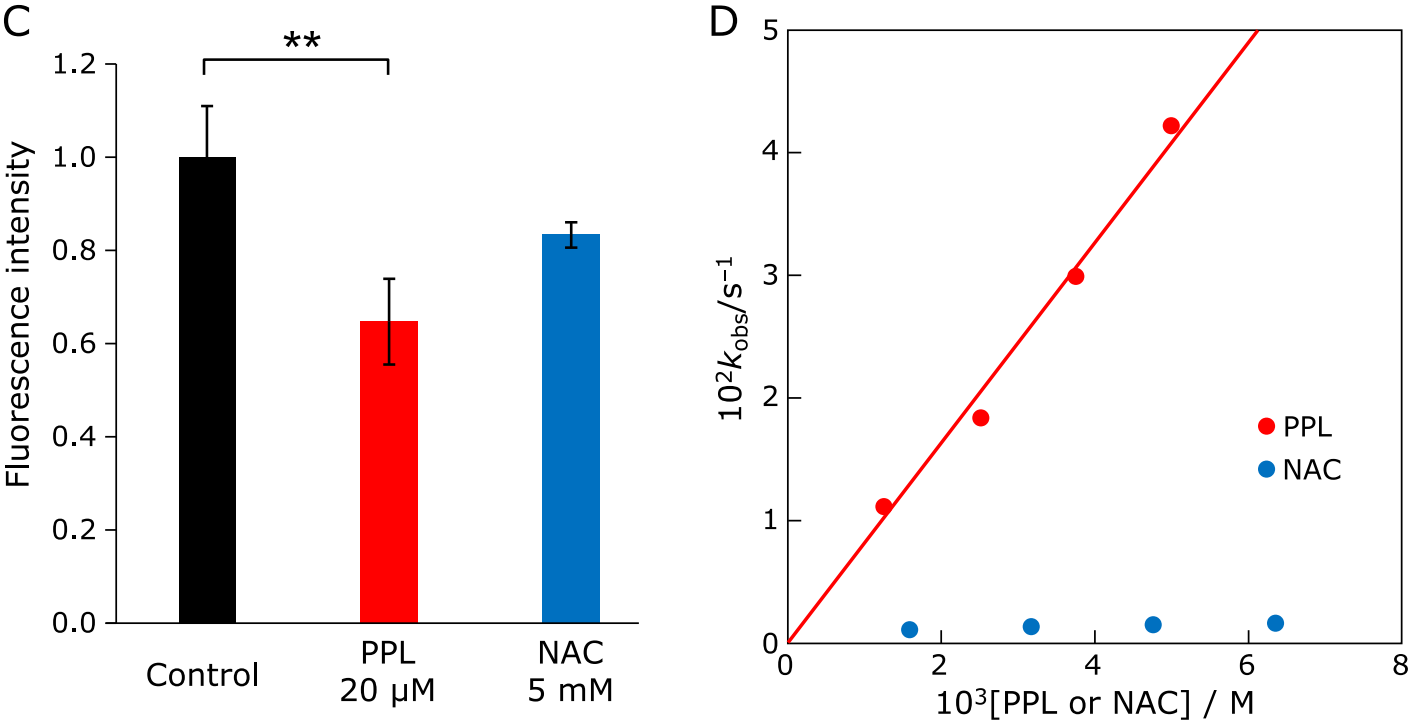

Fig. 1. Cytotoxicity, cell localization and antioxidant activity of PPL in E0771 cells. (A) Colony formation assay of cells treated with PPL for $48 \mathrm{~h}$ at the indicated concentrations. (B) Confocal laser micrograph of PPL intracellular uptake in cells after PPL treatment (50 $\mu \mathrm{M}, 48 \mathrm{~h}$ ). (C) Cellular ROS measurement after 24-h treatment with PPL or NAC at indicated concentrations, using DCFDA staining. (D) DPPH assay of PPL and NAC antioxidant activities, showing $k_{\text {obs }}$ for PPL or NAC with DPPH in MeCN at $25^{\circ} \mathrm{C}$. White bar: $10 \mu \mathrm{m}$. Error bars: SD, ${ }^{*} p<0.01$.

were measured after $24 \mathrm{~h}$ of PPL or NAC treatment. PPL eliminated more intracellular ROS, and at lower concentrations, than did NAC (Fig. 1C).

Antioxidant activity of PPL was estimated using the 2,2diphenyl-1-picrylhydrazyl radical (DPPH), which is frequently used as a reactivity model for ROS. Upon mixing PPL with DPPH in MeCN, the absorption band at $519 \mathrm{~nm}$ due to DPPH immediately decreased, with a clear isosbestic point at $423 \mathrm{~nm}$. This indicates that PPL efficiently scavenged DPPH. The decay of absorbance at $519 \mathrm{~nm}$ obeyed pseudo-first-order kinetics, when the concentration of PPL was higher than a 10-fold excess of the DPPH concentration. The pseudo-first-order rate constant $\left(k_{\mathrm{obs}}\right)$ linearly increased with the PPL concentration ([PPL]). The slope of the linear plot indicated that the second-order-rate constant $(k)$ for the reaction between PPL and DPPH was $8.2 \mathrm{M}^{-1} \mathrm{~s}^{-1}$ in MeCN at $25^{\circ} \mathrm{C}$ (Fig. 1D). The $k_{\text {obs }}$ values for the reaction of NAC + DPPH in $\mathrm{MeCN}$ at $25^{\circ} \mathrm{C}$ (determined in the same manner) was much smaller than those for the PPL reaction with DPPH, although no linear correlation between the $k_{\mathrm{obs}}$ values and [NAC] was observed; therefore, the $k$ value could not be determined. These results suggest that PPL is a strong antioxidant with low cytotoxicity, and exerts intracellular antioxidant activity by being taken into cells through lipophilicity.

PPL induces cell-cycle arrest at the $G_{0} / G_{1}$ phase by suppressing Akt. To evaluate the effect of PPL on the cell cycle, cellular DNA contents were analyzed by PI staining and flow cytometry. After PPL treatment for $24 \mathrm{~h}$ or $48 \mathrm{~h}$, cells at the $\mathrm{G}_{0} / \mathrm{G}_{1}$ phase increased, cells at the $\mathrm{S}$ phase decreased slightly and cells at the $\mathrm{G}_{2} / \mathrm{M}$ phase decreased significantly (Fig. 2B). To elucidate the mechanism of cell-cycle progression, we examined Akt protein expression, which is related to cell-cycle regulation. ${ }^{(23)}$ In accordance with cell-cycle arrest, Western blotting showed phosphorylated Akt (Ser473) was significantly downregulated after PPL treatment (Fig. 2C and D: left side). As well as E0771, PPL decreased phosphorylated Akt (Ser473) in human BC MDAMB-231 (Fig. 2C and D: right side). 

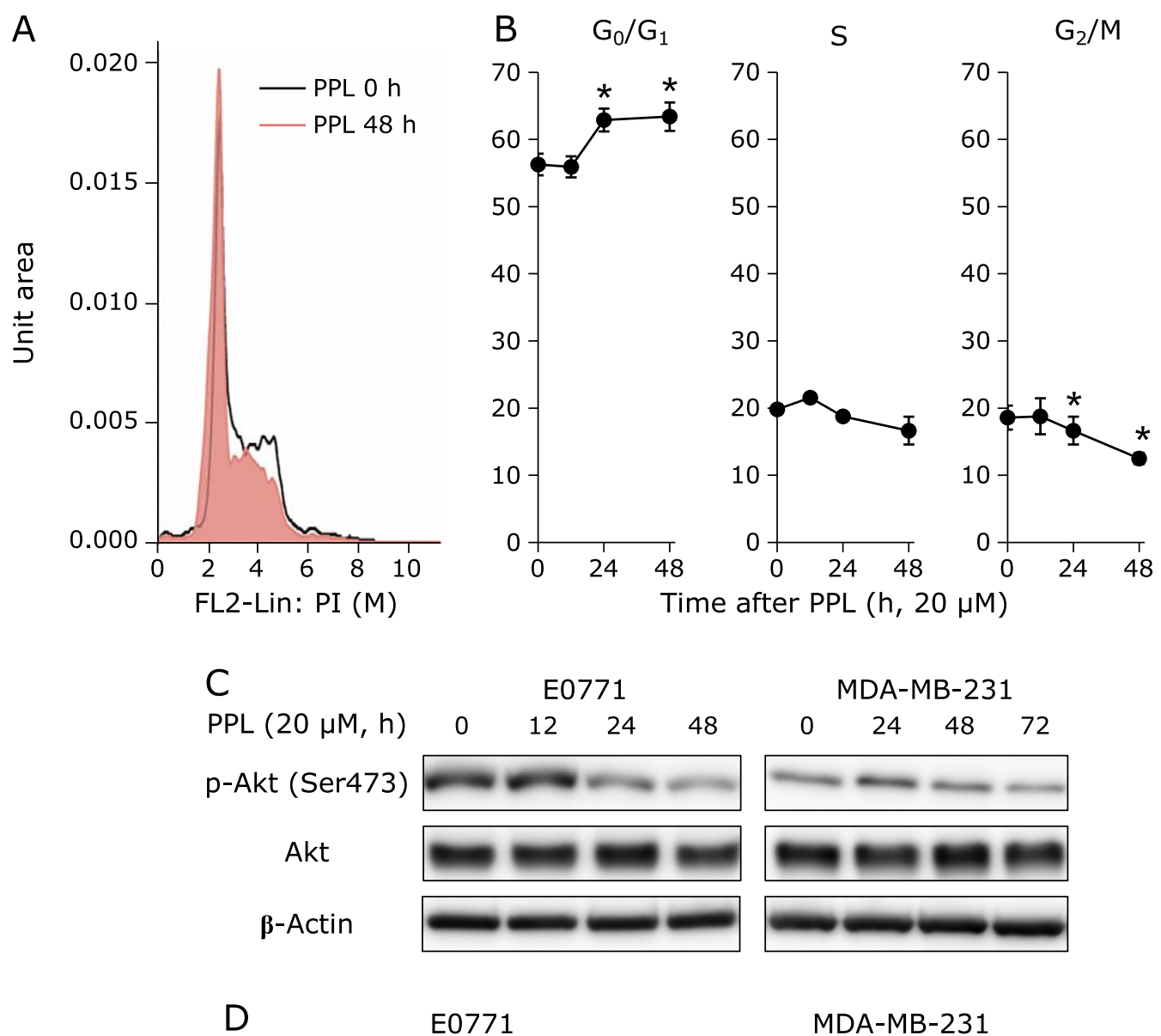

E0771

MDA-MB-231
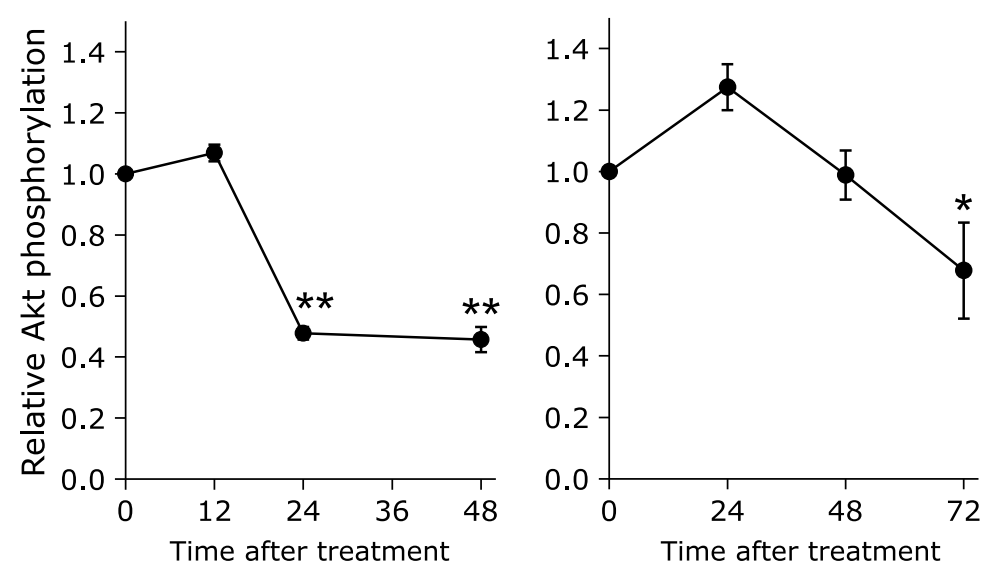

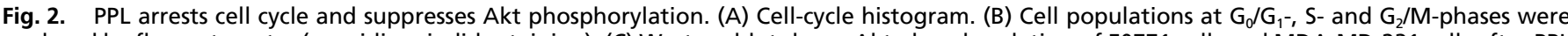
analyzed by flow cytometry (propidium iodide staining). (C) Western blot shows Akt phosphorylation of E0771 cells and MDA-MD-231 cells after PPL treatment $(20 \mu \mathrm{M})$. (C) Representative western blot images of pSer473-Akt, Akt and $\beta$-Actin in E0771 cells and MDA-MB-231 cells. (D) Quantitative analyses of pSer473-Akt and Akt in Western blots of E0771 cells and MDA-MB-231 cells. Error bars: SD, ${ }^{*} p<0.05,{ }^{* *} p<0.01$.

PPL enhances the efficacy of chemotherapy. To examine the chemo-sensitizing effect of PPL, E0771 cells were treated with anti-cancer agents and PPL. Whereas the $\mathrm{IC}_{50}$ of CBDCA alone was $8.89 \mu \mathrm{M}$, it was $5.66 \mu \mathrm{M}$ when combined with PPL. In contrast, NAC significantly reduced the cytotoxicity of CBDCA (Fig. 3A, Table 2). PPL also decreased the $\mathrm{IC}_{50}$ of VCR (VCR alone: $7.64 \mathrm{nM}$, VCR + PPL: $7.08 \mathrm{nM}$ ); and NAC significantly reduced the cytotoxicity of VCR (Fig. 3B, Table 3 ). These results suggest that PPL, unlike NAC, enhances the cytotoxicity of anticancer agents.
PPL suppresses tumor growth and enhances chemotherapy effects. To evaluate the effect of PPL on $\mathrm{BC}$ growth in vivo, mice allografted with E0771 cells were treated with PPL. As shown in Fig. 4A, PPL significantly inhibited tumor growth (Day 22, control: 1,470.2 $\pm 79.7 \mathrm{~mm}^{3}$; PPL: $973.1 \pm 85.9 \mathrm{~mm}^{3}$ ). The group treated with PPL had a longer median survival time compared with the control group (Fig. 4B). Furthermore, PPL had no effect on the weight of E0771 tumor-bearing mice (Fig. 4C). These results suggest that PPL has an antitumor effect with low toxicity. 

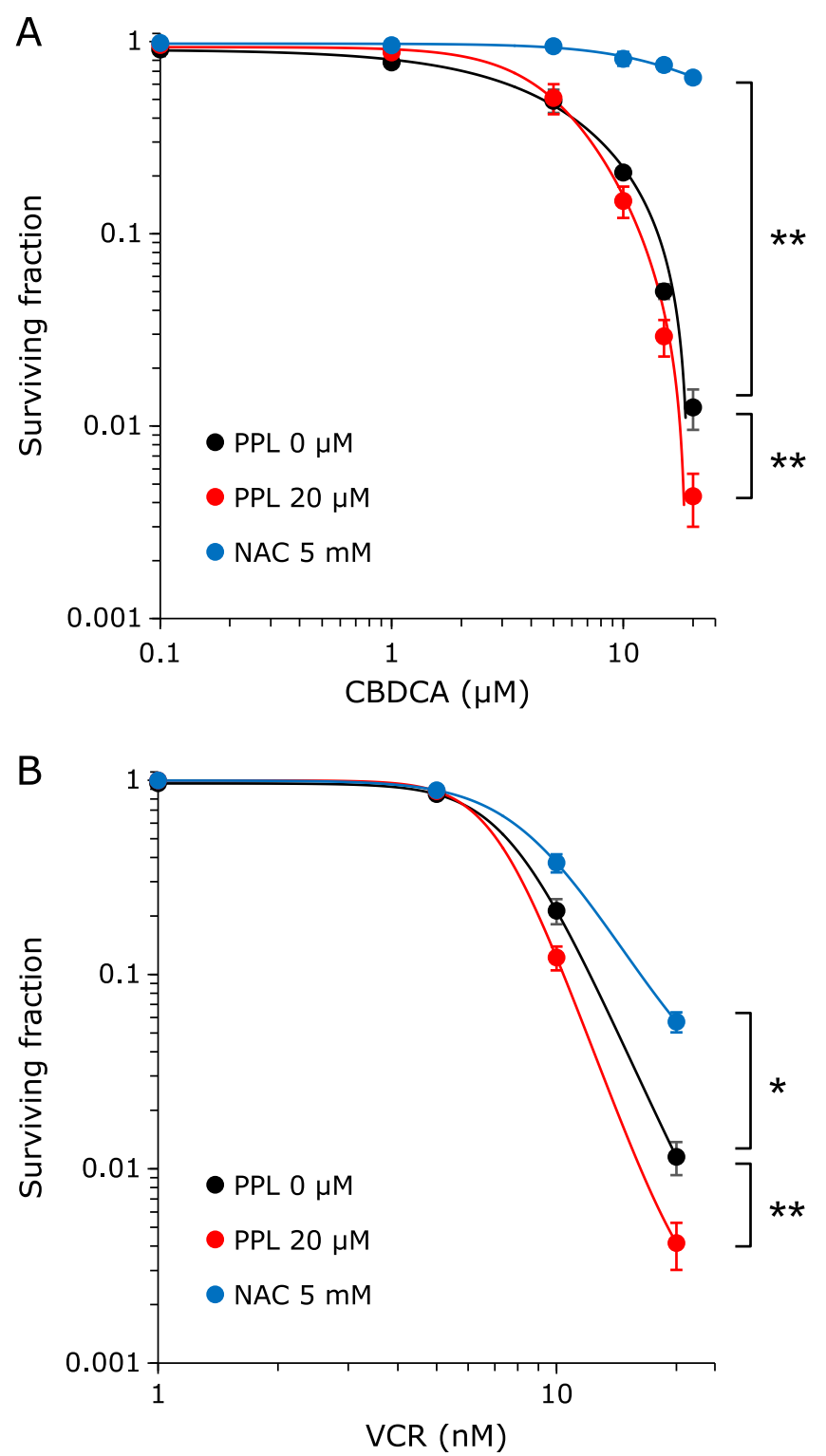

Fig. 3. Colony formation assay shows PPL enhances cytotoxicity of anticancer agents. (A) Colony formation assay in cells simultaneously treated for $48 \mathrm{~h}$ with $20 \mu \mathrm{M}$ PPL + CBDCA, or $5 \mathrm{mM}$ NAC + CBDCA, at the indicated CBDCA concentrations. (B) CFA in cells simultaneously treated for $48 \mathrm{~h}$ with $20 \mu \mathrm{M}$ PPL + VCR or $5 \mathrm{mM}$ NAC + VCR at the indicated VCR concentrations. Error bars: SD, ${ }^{*} p<0.05,{ }^{* *} p<0.01$.

Table 2. $\mathrm{IC}_{50}$ of CBDCA, alone and combined with PPL or NAC

\begin{tabular}{lc}
\hline \multicolumn{2}{c}{$\mathrm{IC}_{50}(\mu \mathrm{M})$} \\
\hline CBDCA & 8.89 \\
PPL + CBDCA & 5.66 \\
NAC + CBDCA & 20.28 \\
\hline
\end{tabular}

CBDCA, carboplatin; $I C_{50}$, half-maximal inhibitory concentration; NAC, $N$-acetyl-L-cysteine.

Table 3. $\mathrm{IC}_{50}$ of VCR, alone and combined with PPL or NAC

\begin{tabular}{|c|c|}
\hline \multicolumn{2}{|c|}{$I C_{50}(n M)$} \\
\hline VCR & 7.64 \\
\hline$P P L+V C R$ & 7.08 \\
\hline $\mathrm{NAC}+\mathrm{VCR}$ & 8.65 \\
\hline
\end{tabular}
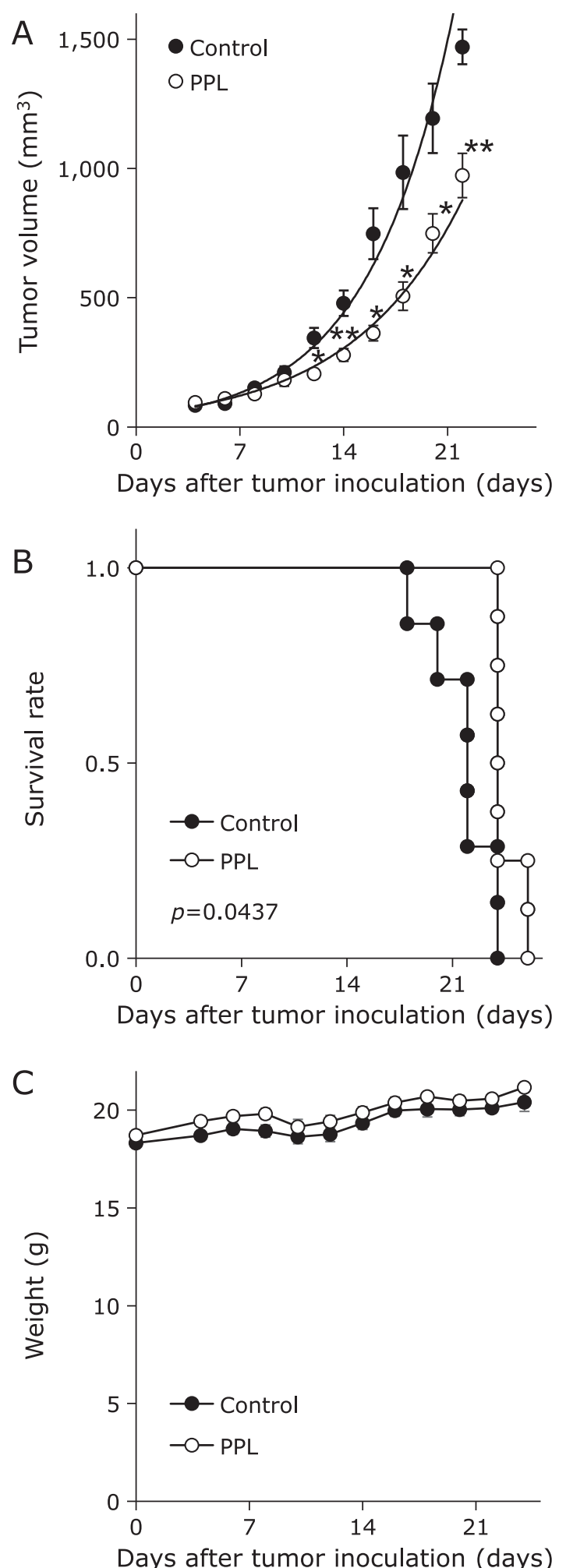

Fig. 4. $\quad P P L$ suppresses transplanted E0771 tumors. Tumors were formed by injecting E0771 cells into mammary fat pads of C57BL/6N mice. (A) E0771 tumor-bearing mice were treated with PPL for 7 consecutive days, and their tumor volumes were measured. (B) Kaplan-Meier survival curves for E0771 tumor-bearing mice treated with PPL. Control group treated with methyl cellulose by oral administration. Survival end point was set when tumor volume $=1,500 \mathrm{~mm}^{3}$. Survival curves of individual groups were compared by log-rank tests. (C) Body weights for E0771 tumor-bearing mice treated with PPL. Error bars: $\mathrm{SE},{ }^{*} p<0.05,{ }^{*} p<0.01$. 

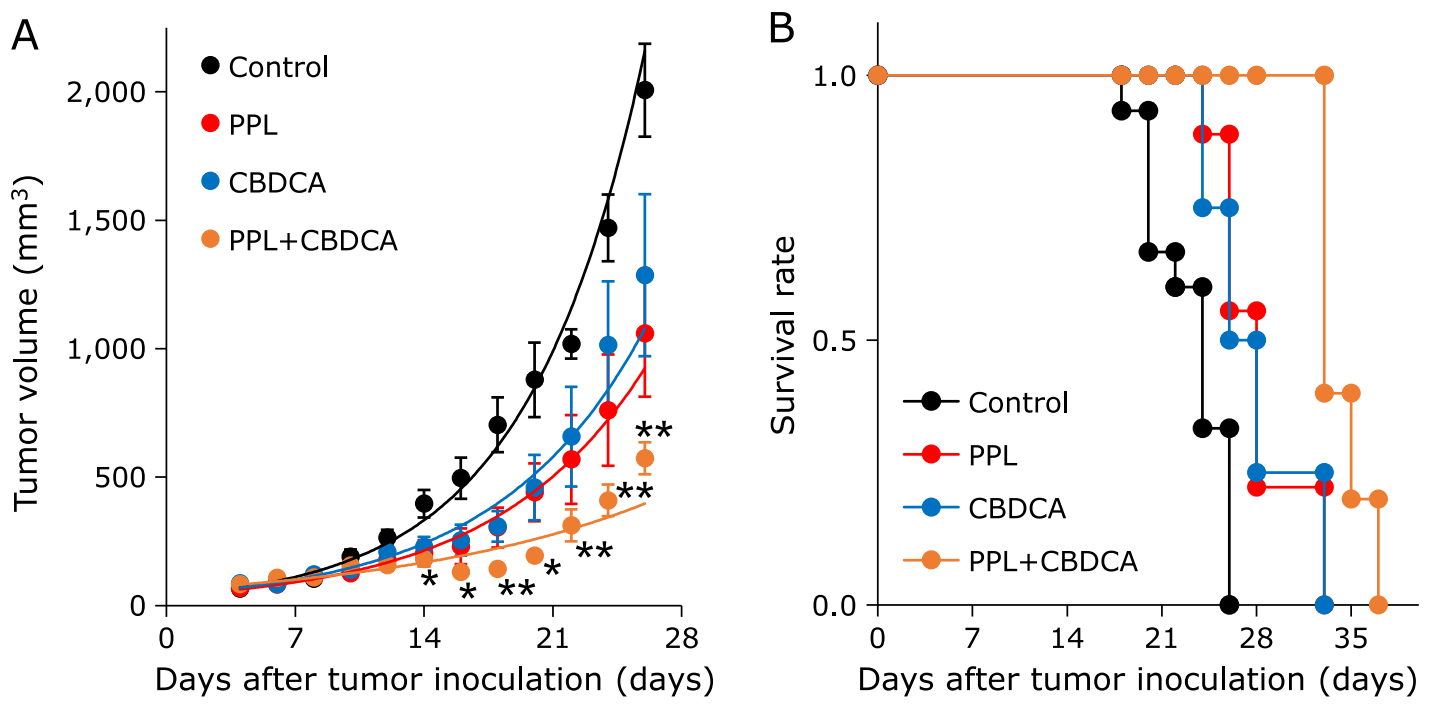

C Control

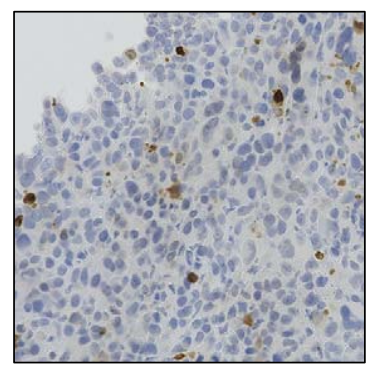

CBDCA

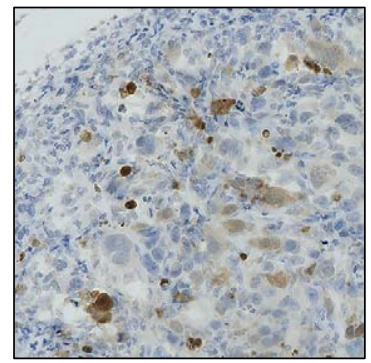

PPL

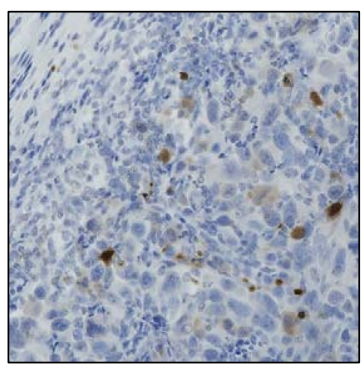

PPL+CBDCA

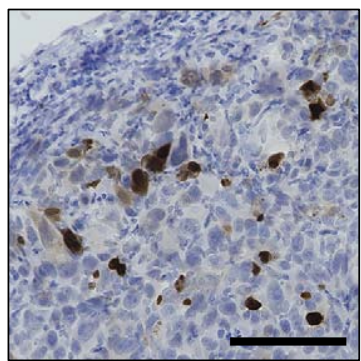

D

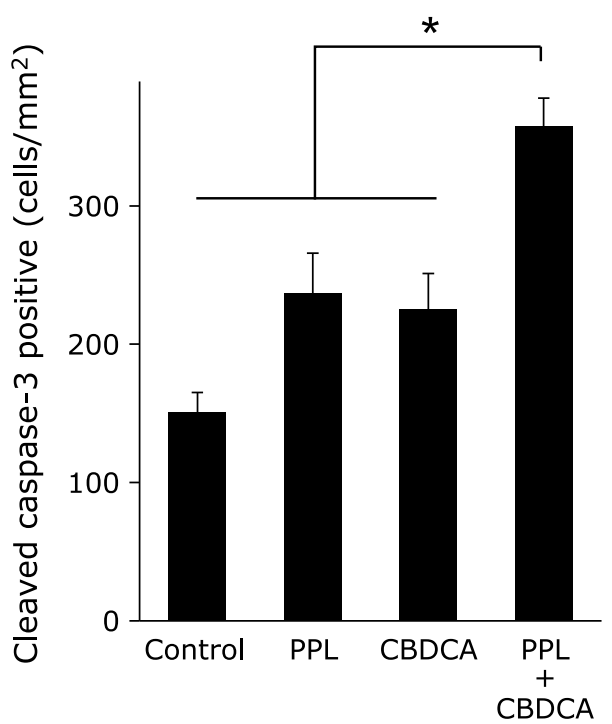

Fig. 5. PPL enhances chemo-sensitization of E0771 tumors. The chemo-sensitizing effect of PPL was evaluated in tumors formed by E0771 cells inoculated into mammary fat pads of C57BL/6N mice. (A) Tumor volumes in E0771 tumor-bearing mice that were treated with PPL for 7 consecutive days, CBDCA once or both PPL and CBDCA. (B) Survival curves for E0771 tumor-bearing mice treated with PPL, CBDCA or both. (C) Immunohistochemical staining for cleaved caspase-3 in allograft E0771 tumors. (D) Cleaved caspase- $3^{+}$cells per mm ${ }^{2}$ were quantified by counting in 10 random microscopic fields. Error bars: $\mathrm{SE},{ }^{*} p<0.05,{ }^{*} p<0.01$. Black bar: $100 \mu \mathrm{m}$. Control group treated with methyl cellulose by oral administration and saline by intraperitoneally administration.

As PPL increased cytotoxicity of anticancer agents in vitro, we evaluated the effect of PPL and CBDCA on transplanted E0771 tumors. As shown in Fig. 5A, CBDCA decreased tumor growth, but the combination of PPL + CBDCA inhibited tumor growth to a greater extent (Day 22, CBDCA: $657.5 \pm 194.4 \mathrm{~mm}^{3}$, PPL + CBDCA: $\left.312.2 \pm 62.5 \mathrm{~mm}^{3}\right)$. The combination group also had longer median survival time (Fig. 5B, Table 4). In addition, immunohistochemical analysis showed that PPL increased tumor cell apoptosis to approximately $157 \%$ compared with controlssimilar to CBDCA (approximately 149\%) - and the combination of PPL + CBDCA induced the highest rate of tumor cell apoptosis to approximately $238 \%$ (Fig. $5 \mathrm{C}$ and D). These results suggest that PPL exerts antitumor effects and sensitizes cancer cells toward chemotherapy in this model.
Table 4. $P$ values for survival rates of each treatment group

\begin{tabular}{lc}
\hline \multicolumn{1}{c}{ vs } & $p$ value \\
\hline Control vs PPL & 0.0008 \\
Control vs CBDCA & 0.0267 \\
Control vs PPL + CBDCA & 0.0004 \\
PPL vs CBDCA & 0.8969 \\
PPL vs PPL + CBDCA & 0.0067 \\
CBDCA vs PPL + CBDCA & 0.0193
\end{tabular}

CBDCA, carboplatin. 


\section{Discussion}

Polyphenols are micronutrients found in various vegetables and fruit. ${ }^{(24)}$ Some polyphenols can reportedly affect degenerative diseases such as cancer and cardiovascular diseases. ${ }^{(25-27)}$ In this study, PPL showed cytoplasmic accumulation and strong antioxidant activity. The PPL also arrested the cell cycle at $\mathrm{G}_{0} / \mathrm{G}_{1}$ by suppressing Akt phosphorylation, leading sensitizing the effect of anticancer agents.

Natural antioxidants have been widely studied in recent years for their prophylactic and therapeutic potential in many diseases. ${ }^{(28)}$ In the present study, PPL accumulated in the cytoplasm due to its high lipophilicity (Fig. 1B), and eliminated cytoplasmic ROS (Fig. 1C) through the strong antioxidant activity shown in the DPPH assay (Fig. 1D).

The PI3K/Akt/mTOR signaling pathway regulates cell metabolism, proliferation and growth; it is mutated in more than $70 \%$ of BC patients. ${ }^{(29)}$ PPL treatment decreased phosphorylation of Akt at Ser473. Serine/threonine kinase Akt regulates a wideranging signaling network. Akt is phosphorylated at the catalytic domain Thr308 by phosphoinositide-dependent kinase $1,{ }^{(30)}$ but requires phosphorylation of Ser473 by mTORC2 for full activation. ${ }^{(31)}$ Activated Akt targets downstream signaling substrates that control processes related to tumor development, including regulators of apoptosis, gene transcription, cell-cycle progression, and cell metabolism. ${ }^{(32)}$ As such, Akt is a promising target among developers of kinase inhibitors. ${ }^{(33)}$ To support the above interaction, PPL induced $\mathrm{G}_{0} / \mathrm{G}_{1}$ arrest in E0771 cells (Fig. 2). Therefore, dephosphorylation of Akt by PPL may have antitumor effects through a variety of Akt-controlled signals, including cell-cycle regulation. ${ }^{(23)}$

In this study, CBDCA and VCR were used as anti-cancer agents. CBDCA and VCR induce apoptosis in cancer cells via ROS accumulation. ${ }^{(34,35)}$ NAC has been shown to promote survival of cancer cells by removing intracellular ROS. ${ }^{(36)}$ As shown in Fig. 3, NAC decreased, and PPL increased, the cytotoxicity of anticancer agents. These results suggest that NAC suppresses

\section{References}

1 Zhou Y, Li Y, Zhou T, Zheng J, Li S, Li HB. Dietary natural products for prevention and treatment of liver cancer. Nutrients 2016; 8: 156.

2 Fu L, Xu B-T, Xu X-R, Qin X-S, Gan R-Y, Li HB. Antioxidant capacities and total phenolic contents of 56 wild fruits from South China. Molecules 2010; 15: 8602-8617.

3 Recio MC, Andujar I, Rios JL. Anti-inflammatory agents from plants: progress and potential. Curr Med Chem 2012; 19: 2088-2103.

4 Andriantsitohaina R, Auger C, Chataigneau T, et al. Molecular mechanisms of the cardiovascular protective effects of polyphenols. Br J Nutr 2012; 108: 1532-1549.

5 Murakami A, Ohnishi K. Target molecules of food phytochemicals: food science bound for the next dimension. Food Funct 2012; 3: 462-476.

6 Dini I, Tenore GC, Dini A. New polyphenol derivative in Ipomoea batatas tubers and its antioxidant activity. J Agric Food Chem 2006; 54: 8733-8737.

7 Ishiguro K, Yahara S, Yoshimoto M. Changes in polyphenolic content and radical-scavenging activity of sweet potato (Ipomoea batatas L.) during storage at optimal and low temperatures. J Agric Food Chem 2007; 55: 10773-10778.

8 Yunoki K, Musa R, Kinoshita M, Tazaki H, Oda Y, Ohnishi M. Presence of higher alcohols as ferulates in potato pulp and its radical-scavenging activity. Biosci Biotechnol Biochem 2004; 68: 2619-2622.

9 Jayaprakasam B, Vanisree M, Zhang Y, Dewitt DL, Nair MG. Impact of alkyl esters of caffeic and ferulic acids on tumor cell proliferation, cyclooxygenase enzyme, and lipid peroxidation. J Agric Food Chem 2006; 54: 53755381.

10 Bray F, Ferlay J, Soerjomataram I, Siegel RL, Torre LA, Jemal A. Global cancer statistics 2018: GLOBOCAN estimates of incidence and mortality worldwide for 36 cancers in 185 countries. CA Cancer J Clin 2018; 68: 394 424. cell death by removing ROS induced by CBDCA or VCR. It is well documented that inhibition of PI3k/Akt pathway enhances chemosensitivity. ${ }^{(37,38)}$ Therefore, the increase in cytotoxicity of CBDCA and VCR from PPL is thought to depend more on Akt dephosphorylation than on the removal of intracellular ROS. In the E0771 tumor model, tumor volume was significantly decreased under PPL treatment, but body weight was not affected (Fig. 4). In addition, as shown in Fig. 5, PPL enhanced the antitumor effect of CBDCA by inducing apoptosis. Therefore, PPL could be a safe anticancer and chemo-sensitizing agent.

Our data provide evidences for the antitumor effects of PPL in $\mathrm{BC}$, and for its sensitizing effect for cancer drugs, which suggests that PPL could be a useful complement to cancer treatment. Some caffeic acid derivatives reported to exhibit antioxidant and antitumor activity and to enhance cytotoxicity of antitumor agents. ${ }^{(39-41)}$ However, the effect of caffeic acid derivatives contained in PPL is not clear. Therefore, further studies are needed to determine the candidate compound of Akt inhibition, and their possible clinical applicability.

\section{Acknowledgments}

We thank Marla Brunker, from Edanz Group (www.edanzediting. com/ac), for editing a draft of this manuscript.

\section{Funding}

This work was supported by Japan Society for the Promotion of Science (JSPS) KAKENHI Grant Numbers JP 19K20452, and Private University Research Branding Project (Ministry of Education, Culture, Sports, Science and Technology, Japan).

\section{Conflict of Interest}

PPL was manufactured by Genuine R\&D Co., Ltd. (Masakatsu Miyanabe, Shinobu Hiraki, Xiaolin Luo). Other authors declare no conflict of interest.

11 Chew HK. Adjuvant therapy for breast cancer: who should get what? West $J$ Med 2001; 174: 284-287.

12 Wagstaff AJ, Ward A, Benfield P, Heel RC. Carboplatin. A preliminary review of its pharmacodynamic and pharmacokinetic properties and therapeutic efficacy in the treatment of cancer. Drugs 1989; 37: 162-190.

13 Bradley WG, Lassman LP, Pearce GW, Walton JN. The neuromyopathy of vincristine in man. Clinical, electrophysiological and pathological studies. $J$ Neurol Sci 1970; 10: 107-131.

14 Singh M, Alavi A, Wong R, Akita S. Radiodermatitis: a review of our current understanding. Am J Clin Dermatol 2016; 17: 277-292.

15 Bava SV, Puliyappadamba VT, Deepti A, Nair A, Karunagaran D, Anto RJ. Sensitization of taxol-induced apoptosis by curcumin involves downregulation of nuclear factor-kappaB and the serine/threonine kinase Akt and is independent of tubulin polymerization. J Biol Chem 2005; 280: 6301-6308.

16 Nagane M, Kanai E, Shibata Y, et al. Sulfasalazine, an inhibitor of the cystine-glutamate antiporter, reduces DNA damage repair and enhances radiosensitivity in murine $\mathrm{B} 16 \mathrm{~F} 10$ melanoma. PLoS One 2018; 13: e0195151.

17 Belmonte F, Das S, Sysa-Shah P, et al. ErbB2 overexpression upregulates antioxidant enzymes, reduces basal levels of reactive oxygen species, and protects against doxorubicin cardiotoxicity. Am J Physiol Heart Circ Physiol 2015; 309: H1271-H1280.

18 Nakanishi I, Kawashima T, Ohkubo K, et al. Electron-transfer mechanism in radical-scavenging reactions by a vitamin E model in a protic medium. Org Biomol Chem 2005; 3: 626-629.

19 Yasui H, Yamamoto K, Suzuki M, et al. Lipophilic triphenylphosphonium derivatives enhance radiation-induced cell killing via inhibition of mitochondrial energy metabolism in tumor cells. Cancer Lett 2017; 390: 160 167.

20 Nagane M, Kuppusamy ML, An J, et al. Ataxia-telangiectasia mutated 
(ATM) kinase regulates eNOS expression and modulates radiosensitivity in endothelial cells exposed to ionizing radiation. Radiat Res 2018; 189: 519528.

21 Nagane M, Yasui H, Sakai Y, et al. Activation of eNOS in endothelial cells exposed to ionizing radiation involves components of the DNA damage response pathway. Biochem Biophys Res Commun 2015; 456: 541-546.

22 Nagane M, Yasui H, Yamamori T, et al. Radiation-induced nitric oxide mitigates tumor hypoxia and radioresistance in a murine SCCVII tumor model. Biochem Biophys Res Commun 2013; 437: 420-425.

23 Ramaswamy S, Nakamura N, Vazquez F, et al. Regulation of G1 progression by the PTEN tumor suppressor protein is linked to inhibition of the phosphatidylinositol 3-kinase/Akt pathway. Proc Natl Acad Sci US A 1999; 96: 2110 2115.

24 Manach C, Scalbert A, Morand C, Rémésy C, Jiménez L. Polyphenols: food sources and bioavailability. Am J Clin Nutr 2004; 79: 727-747.

25 Wang TT, Hudson TS, Wang TC, et al. Differential effects of resveratrol on androgen-responsive LNCaP human prostate cancer cells in vitro and in vivo. Carcinogenesis 2008; 29: 2001-2010.

26 Moore J, Yousef M, Tsiani E. Anticancer effects of rosemary (Rosmarinus officinalis L.) extract and rosemary extract polyphenols. Nutrients 2016; 8: 731.

27 Xia N, Daiber A, Förstermann U, Li H. Antioxidant effects of resveratrol in the cardiovascular system. Br J Pharmacol 2017; 174: 1633-1646.

28 Ratnam DV, Ankola DD, Bhardwaj V, Sahana DK, Kumar MN. Role of antioxidants in prophylaxis and therapy: a pharmaceutical perspective. $J$ Control Release 2006; 113: 189-207.

29 Miller TW, Rexer BN, Garrett JT, Arteaga CL. Mutations in the phosphatidylinositol 3-kinase pathway: role in tumor progression and therapeutic implications in breast cancer. Breast Cancer Res 2011; 13: 224.

30 Song G, Ouyang G, Bao S. The activation of Akt/PKB signaling pathway and cell survival. J Cell Mol Med 2005; 9: 59-71.

31 Riaz A, Zeller KS, Johansson S. Receptor-specific mechanisms regulate phosphorylation of AKT at Ser473: role of RICTOR in $\beta 1$ integrin-mediated cell survival. PLoS One 2012; 7: e32081.

32 Crowell JA, Steele VE, Fay JR. Targeting the AKT protein kinase for cancer chemoprevention. Mol Cancer Ther 2007; 6: 2139-2148.
33 Arencibia JM, Pastor-Flores D, Bauer AF, Schulze JO, Biondi RM. AGC protein kinases: from structural mechanism of regulation to allosteric drug development for the treatment of human diseases. Biochim Biophys Acta 2013; 1834: 1302-1321.

34 He PJ, Ge RF, Mao WJ, Chung PS, Ahn JC, Wu HT. Oxidative stress induced by carboplatin promotes apoptosis and inhibits migration of $\mathrm{HN}-3$ cells. Oncol Lett 2018; 16: 7131-7138.

35 Groninger E, Meeuwsen-De Boer GJ, De Graaf SS, Kamps WA, De Bont ES. Vincristine induced apoptosis in acute lymphoblastic leukaemia cells: a mitochondrial controlled pathway regulated by reactive oxygen species? Int $J$ Oncol 2002; 21: 1339-1345.

36 Sayin VI, Ibrahim MX, Larsson E, Nilsson JA, Lindahl P, Bergo MO. Antioxidants accelerate lung cancer progression in mice. Sci Transl Med 2014; 6: $221 \mathrm{ra} 215$.

37 Nie C, Qin X, Li X, et al. CACNA2D3 enhances the chemosensitivity of esophageal squamous cell carcinoma to cisplatin via inducing $\mathrm{Ca}^{2+}$-mediated apoptosis and suppressing PI3K/Akt pathways. Front Oncol 2019; 9: 185.

38 Bi Y, Li H, Yi D, et al. Cordycepin augments the chemosensitivity of human glioma cells to temozolomide by activating AMPK and inhibiting the AKT signaling pathway. Mol Pharm 2018; 15: 4912-4925.

39 Ma Y, Zhang JX, Liu YN, et al. Caffeic acid phenethyl ester alleviates asthma by regulating the airway microenvironment via the ROS-responsive MAPK/Akt pathway. Free Radic Biol Med 2016; 101: 163-175.

40 Chiang EP, Tsai SY, Kuo YH, et al. Caffeic acid derivatives inhibit the growth of colon cancer: involvement of the PI3-K/Akt and AMPK signaling pathways. PLoS One 2014; 9: e99631.

41 Tolba MF, Esmat A, Al-Abd AM, et al. Caffeic acid phenethyl ester synergistically enhances docetaxel and paclitaxel cytotoxicity in prostate cancer cells. IUBMB Life 2013; 65: 716-729.

This is an open access article distributed under the terms of the Creative Commons Attribution-NonCommercial-NoDerivatives License (http://creativecommons.org/licenses/by-nc-nd/4.0/). 